\title{
Epidemiology of Urban Traffic Accident Victims Hospitalized More Than 24 Hours in a Level III Trauma Center, Kashan County, Iran, During 2012-2013
}

\author{
Mehrdad Mahdian ${ }^{1}$; Mojtaba Sehat ${ }^{1, *}$; Mohammad Reza Fazel ${ }^{1}$; Alireza Moraveji ${ }^{1}$; Mahdi \\ Mohammadzadeh $^{1}$ \\ ${ }^{1}$ Trauma Research Center, Kashan University of Medical Sciences, Kashan, IR Iran \\ *Corresponding author: Mojtaba Sehat, Trauma Research Center, Kashan University of Medical Sciences, Kashan, IR Iran. Tel: +98-3155620634, E-mail: om_sehat@yahoo.com
}

Received: March 6, 2015; Revised: April 13, 2015; Accepted: April 19, 2015

\begin{abstract}
Background: Urban traffic accidents are an extensively significant problem in small and busy towns in Iran. This study tried to explore the epidemiological pattern of urban traffic accidents in Kashan and Aran-Bidgol cities, Iran.

Objectives: This study aimed to assess various epidemiological factors affecting victims of trauma admitted to a main trauma center in Iran.

Patients and Methods: During a retrospective study, data including age, sex, injury type and pattern, outcome, hospital stay and treatment expenditures regarding urban Road Traffic Accidents (RTAs) for one year (March 2012-March 2013) were obtained from the registry of trauma research center, emergency medical services and deputy of health of Kashan University of Medical Sciences. One-way ANOVA and chi-square tests were used to analyze data using SPSS version 16.0. P value $<0.05$ was considered significant.

Results: A total of 1723 victims (82.6\% male, sex ratio of almost 5:1) were considered in this study. Mortality rate in trauma cases hospitalized more than 24 hours during our study was $0.8 \%$. Young motorcyclist men with the rate of more than 103 per 10000 were the most vulnerable group. The most common injury was head injury (73.6\%) followed by lower limb injury(33.2\%). A significant association was found between mechanism of injury and head, lower limb, multiple injuries and high risk age group.

Conclusions: Urban RTAs are one of the most important problems in Kashan and Aran-Bidgol cities, which impose a great economic burden on health system. Motorcyclists are the most vulnerable victims and multiple trauma and head injury are seen among them extensively.
\end{abstract}

Keywords: Accidents; Epidemiology; Injury; Traffic

\section{Background}

Urban growth and urbanization has been the most striking feature of recent world developments. Whereas an urbanization rate in many developed countries is fixed, the rate of urban growth has been increasing in most developing countries including Iran. The rate of urbanization in Iran was estimated about $2.5 \%$ in 2011 (1). This high urbanization rate experienced in developing countries poses great challenges including increased density of vehicles and in turn, increased risk of traffic accidents. Road Traffic Accidents (RTAs) in Iran represent an excessively high percentage of country's fatalities. According to the UNICEF report, RTAs kill about 1.2 million people every year and disable 20 - 50 million people globally, but the rate of road accidents in Iran is twenty times more than the world's average. Road traffic accidents kill nearly 28000 people in Iran each year and they are responsible for more than 300000 injuries and disabilities (2). In many developing countries including Iran, documentation of health statistics is poor and information is limited, therefore, the effects of trauma on urban population are poorly understood (3-5). Kashan University of Medical Sciences, as a part of health service sys- tem in Iran, is responsible for providing health services for more than 400000 populations in the center of Iran. It has an Emergency Medical Services (EMS), a trauma research center with a trauma registry and also a major hospital that provides trauma care. This study aimed to clarify characteristics of traffic injury in Kashan County including Aran-Bidgol City that represents cities with the same population in central Iran. Increasing our knowledge about characteristics of these injuries would lead to more appropriate interventions by authorities and reducing the burden of such unpleasant events.

\section{Objectives}

The aim of this study was to assess various epidemiological factors that influence victims of trauma admitted to a main trauma center in the center of Iran.

\section{Patients and Methods}

This retrospective cross-sectional study was conducted at a trauma research center, affiliated to Kashan University of Medical Sciences, Iran, during March 22, 2012 and

Copyright (C) 2015, Kashan University of Medical Sciences. This is an open-access article distributed under the terms of the Creative Commons Attribution-NonCommercial 4.0 International License (http://creativecommons.org/licenses/by-nc/4.0/) which permits copy and redistribute the material just in noncommercial usages, provided the original work is properly cited. 
Mahdian $M$ et al.

March 22, 2013 after obtaining an approval from the Institute Research Board. All one-year EMS, trauma research center and deputy of health of Kashan University of Medical Sciences' records in the study period were considered regarding demographic characteristics of patients, organ injury, prehospital intervention, treatment expenditure and outcome. Based on the International Classification of Diseases and Causes of Death (ICD 10), traffic accidents are classified under the V01-V99 codes. All intra-city traffic accidents in Kashan and Aran-Bidgol involving at least a vehicle with two wheels leading to hospitalization more than 24 hours were included in our study. Patients from outside of Kashan and Aran-Bidgol cities were excluded from the study. All information gathered from different sources refined to remove duplicate cases. Due to coverage of all medical centers in the region, we expected that our data could be representative of Kashan County. Duplicates were removed for name (first name, surname and father's name) and date of accident. The ICD-10 diagnosis codes were extracted from the database of our research center for organ injury analysis. One-way ANOVA and chi-square tests were used for data analysis using SPSS software version 16.0. P value $<0.05$ was considered as significant.

\section{Results}

During the study period, 9414 cases were recorded as victims of traffic accidents in the streets of Kashan (6989)and Aran-Bidgol (2425) cities. Therefore, based on the population of the Kashan County, reported by the deputy of health of Kashan University of Medical Sciences in 2012 (406010), the urban RTA rate was $2.3 \%$. This rate for cases hospitalized more than 24 hours was $0.4 \%$. On the other hand, according to Statistics Centre of Iran, the total number of motorcycles and cars in Kashan in 2011 were 64419 and 51351, respectively (6). Consequently, we concluded that about $1.9 \%$ of motorcyclists have been hospitalized more than 24 hours due to traffic accidents. This rate was $0.3 \%$ for car owners. Among total cases, 6163 (65.5\%) received care by EMS service, 996 cases in the scene of incident and 5167 (84\%) transferred to the hospital. More than one-fourth of casualties were conveyed to the hospital by private vehicles without receiving any specialized care. In total, 2014 cases were hospitalized more than 24 hours of which 291 cases were excluded from the study due to incomplete recorded data. Therefore, a total of 1723 victims (82.6\% male, sex ratio of almost 5:1) were considered during this study in our level III trauma center hospital regarding intra-city accidents. Table 1 shows demographic profile of casualties. The average length of hospital stay was 3.3 ( $\mathrm{SE}=0.1)$ days. Total hospitalization cost was more than $10,000,000,000$ Iranian Rials (almost equal to $\$ 345000$ US; average costs of each hospitalized casualty were \$200 US). During the study period, 33 cases died due to urban traffic accidents, 12 people at the scene, 6 cases at emergency department and less than 24 hours of hospitalization, while 15 cases deceased after 24 hours of hospitalization, whose data were assessed by the current study. Most people who died were over 60 years old (60\%), followed by the age group of 15 - 30 years (20\%). Educational level of the injured people was also considered. Most victims were educated at high school level followed by primary and junior high school (Table 1). From a total of 247 pedestrian victims, 113 (45.7\%) had motorcycle accident and the rest were injured by car. Based on the rate of injuries among RTA victims, young adults (the age group 15 - 30 years) were the most vulnerable group to urban traffic accidents, followed by over 60 years (Table 2). Near two-third of urban RTAs accounted for motorcycle accidents and young male motorcyclists (15 30 years) with the accident rate of more than 103 per 10000 populations as the most vulnerable group. The most susceptible group in women, for urban RTAs, overall (with the rate of 23.7/10000) and head trauma cases (with the rate of 6.5/10000) specifically, were older (> 60 years) people (Table 2). A significant difference was found between RTA victims either generally or specifically in motorcyclists regarding age and sex (Table 2). As seen in Table 3, chi-square test showed a significant association between mechanism of injury and factors including sex, the high-risk age group (Age $<15$ and $>60$ years), multiple, and lower limb injuries (all $\mathrm{P}<0.001)$ and head injury $(\mathrm{P}=0.04)$.

Table 1. Demographic and Injury Variables in Cases Hospitalized More Than 24 Hours in Kashan Shahid-Beheshti Hospital Between March 22, 2012 and March 22, $2013^{\mathrm{a}}$

\begin{tabular}{|lc}
\hline Variables & Frequency \\
\hline Age, $\mathbf{y}$ & $31.46 \pm 17.8$ \\
\hline Gender & \\
\hline Male & $1424(82.6)$ \\
\hline Female & $299(17.4)$ \\
\hline Educational status & \\
\hline Child (before going to school) & $85(4.9)$ \\
\hline Illiterate & $43(2.5)$ \\
\hline Primary and junior high school & $612(35.5)$ \\
\hline Senior high school & $945(54.9)$ \\
\hline Higher education & $38(2.2)$ \\
\hline Mode of injury & \\
\hline Pedestrian & $247(14.3)$ \\
\hline Motorcycle & $1264(73.4)$ \\
\hline Bicycle & $45(2.6)$ \\
\hline Car & $166(9.6)$ \\
\hline Truck & $1(0.1)$ \\
\hline Pattern of injury & \\
\hline Multiple trauma & $523(30.4)$ \\
\hline Head injury & $610(35.4)$ \\
\hline Spinal injury & $53(3.1)$ \\
\hline Chest injury & $20(1.2)$ \\
\hline Abdomen injury & $7(0.4)$ \\
\hline Upper limb injury & $417(24.2)$ \\
\hline Lower limb injury & $572(33.2)$ \\
\hline a Data are presented as No.(\%) or Mean \pm SD. & \\
\hline
\end{tabular}


Mahdian $M$ et al.

\begin{tabular}{|c|c|c|c|}
\hline Age Group & Male (Rate) ${ }^{\mathrm{b}}$ & Female (Rate) $)^{b}$ & PValue \\
\hline Urban RTAs Overall & & & $\mathrm{P}<0.001$ \\
\hline$<15$ & $185(41.1)$ & $49(11.6)$ & \\
\hline $15-30$ & $687(116)$ & $94(15.2)$ & \\
\hline $31-59$ & $419(51.2)$ & $112(14.5)$ & \\
\hline$\geq 60$ & $133(68)$ & $44(23.7)$ & \\
\hline Total & $1424(69.2)$ & $299(14.9)$ & \\
\hline Head injury & & & $P=0.062$ \\
\hline$<15$ & $81(18)$ & $22(5.2)$ & \\
\hline $15-30$ & $216(36.4)$ & $38(6.1)$ & \\
\hline $31-59$ & $138(16.8)$ & $46(6)$ & \\
\hline$\geq 60$ & $57(29.2)$ & $12(6.5)$ & \\
\hline Total & $492(24)$ & $118(5.9)$ & \\
\hline Motorcycle accidents & & & $P=0.019$ \\
\hline$<15$ & $105(23.3)$ & $21(4.9)$ & \\
\hline $15-30$ & $612(103.2)$ & $58(9.4)$ & \\
\hline $31-59$ & $325(39.7)$ & $50(6.4)$ & \\
\hline$\geq 60$ & $82(41.9)$ & $11(5.9)$ & \\
\hline Total & $1124(54.6)$ & $140(7)$ & \\
\hline
\end{tabular}

a Data are presented as No. (\%)

$\mathrm{b}$ Rate per 10000 population.

Table 3. Association Between Mechanism of Injury and Important Variables

\begin{tabular}{|c|c|c|c|c|c|}
\hline Mechanism Variable & Pedestrian Accident & Motorcycle Accident & Car Accident & Bicycle Accident & P Value \\
\hline Age, y $($ Mean \pm SD $)$ & $35.7 \pm 24.9$ & $30.4 \pm 15.6$ & $35.2 \pm 17.1$ & $34 \pm 26.4$ & $<0.001$ \\
\hline Gender & & & & & $<0.001$ \\
\hline Male & $149(60.3)$ & $1124(88.9)$ & $112(67.1)$ & $39(86.7)$ & \\
\hline Female & $98(39.7)$ & $140(11.1)$ & $55(32.9)$ & $6(13.3)$ & \\
\hline Hospital stay (more than 2 days) & $98(39.7)$ & $447(35.4)$ & $68(40.7)$ & $10(22.2)$ & 0.7 \\
\hline High-risk groups, Age $<15$ and $>60$ y & $134(54.3)$ & $219(17.3)$ & $31(18.6)$ & $27(60)$ & $<0.001$ \\
\hline \multicolumn{6}{|l|}{ Type of injury } \\
\hline Multiple injury & $82(33.2)$ & $350(27.7)$ & $80(47.9)$ & $11(24.4)$ & $<0.001$ \\
\hline Head & $102(31.3)$ & $425(33.6)$ & $62(37.1)$ & $21(46.7)$ & 0.04 \\
\hline Upper limb & $46(18.6)$ & $323(25.6)$ & $38(22.8)$ & $10(22.2)$ & 0.1 \\
\hline Lower limb & $82(32.2)$ & $461(36.5)$ & $23(13.8)$ & $6(13.3)$ & $<0.001$ \\
\hline
\end{tabular}

\section{Discussion}

During the study period, 1723 cases were hospitalized for more than 24 hours due to urban traffic accidents. Our study showed that nearly two-thirds of urban RTAs were accounted for motorcycle accidents and young male motorcyclists with the accident rate of more than 103 per 10000 populations as the most vulnerable group. A significant association was found between mechanism of injury and factors including sex, the high-risk age group (Age $<15$ and $>60$ years), multiple, lower limb and head injuries. In the last two decades along with development of higher education institutions and particularly industries and growth of immigration, the population of Kashan and Aran Bidgol Cities were increased. This leads to increased vehicles, especially motorcycles in the city streets (a common problem in small cities in Iran) and consequently a rapid increase of traffic accidents. Road traffic accidents usually affect productive age group in developing countries. In the present study, most admitted 
Mahdian $M$ et al.

patients aged 15 - 30 years (45.3\%) with a mean age of 22.1 \pm 4.2 years. These results are consistent with some other studies $(4,7,8)$ and suggest that this productive class of society should be targeted by the authorities regarding traffic accident reduction programs. Our study showed that the second vulnerable groups to urban traffic accidents are elderly and the highest rate of mortality was observed in this group as well. Age- related changes could affect cognitive and motor functions resulting in slower and more restricted movements and increased reaction time (9). On the other hand, because of the nature of aging, most trauma victims often have more comorbidities and therefore their ability to tolerate injury is decreased $(10,11)$. These problems make them more prone to trauma morbidity and mortality. Education to general population and attitude modification, training, environmental changes like improvement of street structures and facilities, improving motor vehicles designs and vision screening of older drivers (12) are some examples for traffic accident prevention in this age group. Like the results of series of studies, compared with females, males are more vulnerable in traffic accident injuries usually because of their responsibility in the family as householders $(5,13$, 14). More than two-thirds of urban trauma victims in our study were motorcycle drivers, followed by pedestrians. Due to the nature of Iranian small cities (short distances within the city), the use of motorcycles is very common. For this reason, these two classes of society are at risk of traffic accidents and have more serious injuries compared to others like car or truck drivers. Urban streets organizing, identifying specific line for motorcyclists and emphasis on the rights of pedestrian at the crosswalks are just a few examples of what the authorities can do to reduce the burden of urban RTAs. Although the protective role of helmet in motorcyclists is well-known, unfortunately most of them do not use it. Trauma brain injury (TBI), as a serious public health problem, is the most common cause of morbidity and mortality in traumatic patients worldwide, especially in developing countries (13) In our study, most TBI patients (69.7\%) were motorcycle riders. Unfortunately, due to various reasons people do not wear helmets. Scorching heat, feeling less likely crash in short distances by motorcyclists, fear of stealing on leaving the motorcycle are some reasons that people do not wear helmets (15, 16). Only a small number of motorcyclists (3.1\%) wear helmet in Kashan according to the study of Paravar et al. (17). Reforming laws on the use of helmets, adapting helmets based on local climate, education along with voluntarily encouragement of wearing helmet would be advantageous. Our study showed that only $2.2 \%$ of urban traffic accidents had higher education. Comparable results were reported by the others $(18,19)$. Therefore, qualification of a driving license based on the educational level and investment on public education could be a solution for reducing the impacts of RTAs. Based on our results, more than $60 \%$ of victims were transferred to hospital by EMS. Compared to the results of previous study performed by the same authors (3), the number of victims transferred by EMS were increased about 20\% during a 6-year period. This could be a result of increasing urban EMS bases (from 4 to 6) and also public knowledge about services provided by EMS. Our study showed that pedestrians and cyclists are vulnerable groups regarding urban RTAs. According to the European Commission, even in developed countries, most fatalities, severe and slight injuries to pedestrians and cyclists occur in urban areas. Most pedestrian fatalities occur in children younger than 10 years and adults aged 65 years or older $(20,21)$, comparable with our results that showed children and the elderly as the most vulnerable groups to urban traffic accidents. Designing facilities for pedestrians and cyclists such as pedestrian overpasses in right places and cycle lanes, encouraging cyclists to use instruments to improve their visibility (e.g. pedal and spoke reflectors), determining the minimum age for cycling on public roads, and helmet legislation may reduce the number of crushes and decrease injury severity. The present study showed that more than $45 \%$ of pedestrians were hit by motorcycles. Surprisingly, our findings are different with other reports $(22,23)$ from developed countries, in which pedestrians were hit more by cars than motorcycles. This may be due to a large number of motorcycles in our crowded small city and lack of proper implementation of laws. In conclusion, our study showed that RTAs are one of the most important problems in Kashan and Aran-Bidgol cities, which impose a great financial burden on health system. Motorcyclists are most victims and multiple trauma and head injury as more dangerous complications of traffic accidents are seen among them extensively.

\section{Acknowledgements}

This study was primarily a report from a Ph.D dissertation supported by deputy of research, Kashan University of Medical Sciences (Grant no: 92173). The authors express their gratitude to staff of trauma research center, deputy of health of the university, especially Mr. Habibollah Rahimi, the EMS and medical record unit of Kashan Shahid Beheshti Hospital for their assistance in data gathering.

\section{Financial Disclosure}

This study was a part of a Ph.D dissertation supported by deputy of research, Kashan University of Medical Sciences (Grant no: 92173).

\section{References}

1. Wikipedia.. Urbanization by country. 2015. Available from: http:// en.wikipedia.org/wiki/Urbanization.

2. UNICEF.. Road Traffic Injuries in Iran and their Prevention, A Worrying Picture. 2012. Available from: http://www.unicef.org/iran/ media_4783.html.

3. Fazel MR, Fakharian E, Mahdian M, Mohammadzadeh M, Salehfard L, Ramezani M. Demographic Profiles of Adult Trauma During a 5 Year Period (2007-2011) in Kashan, IR Iran. Archives of Trauma Research. 2012;1(2):1-4.

4. Rastogi D, Meena S, Sharma V, Singh GK. Epidemiology of pa- 
tients admitted to a major trauma centre in northern India. Chin JTraumatol.2014;17(2):103-7.

5. Moafian G, Aghabeigi MR, Heydari ST, Hoseinzadeh A, Lankarani $\mathrm{KB}$, Sarikhani Y. An epidemiologic survey of road traffic accidents in Iran: analysis of driver-related factors. Chin J Traumatol. 2013;16(3):140-4.

6. Statistical Center of Iran. Selected Findings of National Population and Housing Census. 2011. Available from: http://www.sci.org.ir/ SitePages/report_90/ostani/ostani_Family_report_final_permision.aspx.

7. Oginni FO, Ugboko VI, Ogundipe O, Adegbehingbe BO. Motorcycle-related maxillofacial injuries among Nigerian intracity road users. J Oral Maxillofac Surg. 2006;64(1):56-62.

8. Al-Maniri AA, Al-Reesi H, Al-Zakwani I, Nasrullah M. Road traffic fatalities in oman from 1995 to 2009: evidence from police reports. Int J Prev Med. 2013;4(6):656-63.

9. European Network for Safety Among Elderly.. Fact sheet: Prevention of Road Traffic Injuries among Elderly. 1998. Available from: http://www.injuryobservatory.net/wp-content/uploads/2012/08/ OlderRoad-Guide-Prevention-of-Road.pdf.

10. Gowing R, Jain MK. Injury patterns and outcomes associated with elderly trauma victims in Kingston, Ontario. Can J Surg. 2007;50(6):437-44

11. Abou Raya S, ElMeguid LA. Road traffic accidents and the elderly. Geriatr Gerontol Int. 2009;9(3):290-7.

12. Desapriya E, Wijeratne H, Subzwari S, Babul-Wellar S, Turcotte K, Rajabali F, et al. Vision screening of older drivers for preventing road traffic injuries and fatalities. Cochrane Database Syst Rev. 2011(3):CD0 06252.

13. Mishra B, Sinha Mishra ND, Sukhla S, Sinha A. Epidemiological study of road traffic accident cases from Western Nepal. Indian J Community Med. 2010;35(1):115-21.
14. Aenderl I, Gashaw T, Siebeck M, Mutschler W. Head injury-a neglected public health problem: a four-month prospective study at Jimma University specialized hospital, Ethiopia. Ethiop J Health Sci. 2014;24(1):27-34.

15. World helth Organization.. A road safety manual for decisionmakers and practitioners.. Available from: http://www.who.int/ violence_injury_prevention/publications/road_traffic/helmet_ manual.pdf.

16. Faryabi J, Rajabi M, Alirezaee S. Evaluation of the use and reasons for not using a helmet by motorcyclists admitted to the emergency ward of shahid bahonar hospital in kerman. Arch Trauma Res. 2014;3(3):e19122.

17. Paravar M, Hosseinpour M, Salehi S, Mohammadzadeh M, Shojaee A, Akbari H, et al. Pre-hospital trauma care in road traffic accidents in kashan, iran. Arch Trauma Res. 2013;1(4):166-71.

18. Sami A, Moafian G, Najafi A, Aghabeigi MR, Yamini N, Heydari ST, et al. Educational level and age as contributing factors to road traffic accidents. Chin J Traumatol. 2013;16(5):281-5.

19. Tiruneh BT, Dachew BA, Bifftu BB. Incidence of Road Traffic Injury and Associated Factors among Patients Visiting the Emergency Department of Tikur Anbessa Specialized Teaching Hospital, Addis Ababa, Ethiopia. Emerg Med Int. 2014;2014:439818.

20. European Commission.. Mobility and Transport.. Available from http://ec.europa.eu/transport/road_safety/specialist/knowledge/pedestrians/index_en.htm.

21. Chakravarthy B, Lotfipour S, Vaca FE. Pedestrian injuries: emergency care considerations. Cal J Emerg Med. 2007;8(1):15-21.

22. Paulozzi LJ. United States pedestrian fatality rates by vehicle type. Inj Prev. 2005;11(4):232-6.

23. Martin JL, Lardy A, Laumon B. Pedestrian injury patterns according to car and casualty characteristics in france. Ann Adv Automot Med. 2011;55:137-46 